\title{
Silica-calcium zirconate nanocomposite, studying its thermal and electrical properties
}

\author{
NEDA KERMANI ${ }^{1}$, MARYAM KARGAR RAZI ${ }^{1}$, SEYED SAEED MIRZAEE ${ }^{2, *}$ and \\ REZA TAYEBEE ${ }^{3}$ \\ ${ }^{1}$ Department of Chemistry, Azad University Tehran North Branch, Tehran, Iran \\ ${ }^{2}$ Department of Ceramic, Materials and Energy Research Centre, Karaj 3177983634, Iran \\ ${ }^{3}$ Department of Chemistry, School of Sciences, Hakim Sabzevari University, Sabzevar, Iran
}

MS received 1 July 2014; revised 11 October 2014

\begin{abstract}
Silica-calcium zirconate nanocomposite was prepared in a two-step procedure. First, nanocalcium zirconate was synthesized by the modified sol-gel method; then, silica was added to the prepared sol and the resulting product was calcined at $700-1000^{\circ} \mathrm{C}$. Dilatometric measurements were performed to determine the coefficient of thermal expansion $\left(k_{\alpha}\right)$. It was concluded that $k_{\alpha}$ was decreased from $15.96 \times 10^{-6}$ to $10.26 \times 10^{-6} 1^{\circ} \mathrm{C}^{-1}$ with the increase in calcium zirconate/silica ratio. Moreover, studies on the dielectric properties and calcination temperature showed that the dielectric constant $\left(\varepsilon_{\mathrm{r}}\right)$ was increased from 3.9 to 5.7.
\end{abstract}

Keywords. Nanocomposite; silica-calcium zirconate; thermal coefficient expansion; dielectric constant.

\section{Introduction}

Calcium zirconate $\left(\mathrm{CaZrO}_{3}\right)$ is the most stable compound in the $\mathrm{ZrO}_{2}-\mathrm{CaO}$ quasi-binary systems and has received great attention due to its unique characteristics. ${ }^{1} \mathrm{CaZrO}_{3}$ has perovskite structure and bears orthorhombic crystalline lattice. ${ }^{2-4}$ Materials with perovskite structure are well known because of their significant electrical properties, including ferroelectricity, piezoelectricity and superconductivity. Thus, $\mathrm{CaZrO}_{3}$ is a potential candidate for multilayer ceramic capacitors or dielectric resonators, especially at short wavelengths, because of its high dielectric constant and low dielectric loss. ${ }^{5-8}$ Furthermore, high melting point, improved resistance to chemical degradation and slog and low coefficient of thermal expansion of $\mathrm{CaZrO}_{3}$, made it suitable for refractory ceramic applications. ${ }^{9-12}$ Bin et al ${ }^{13}$ reported that the dielectric properties of $\mathrm{BaTiO}_{3}$ can be improved with the addition of $\mathrm{CaZrO}_{3}$. There are different methods for the preparation of $\mathrm{CaZrO}_{3}$, including chemical and ceramic methods. Ceramic methods have a few disadvantages such as large particle size, low surface area, lack of chemical homogeneity and high agglomeration degree. ${ }^{14-16}$ Moreover, chemical approach gains much interest due to its high crystallinity and low temperature. ${ }^{4}$

Different factors can affect the dielectric properties of perovskite ceramics. Among these properties, grain size has attracted great interests. Buessem et $a l^{17}$ reported that the dielectric constant of $\mathrm{BaTiO}_{3}$ increases with the decrease of grain size in the range of $0.8-50 \mu \mathrm{m}$ resulting from the

*Author for correspondence (S_mirzaee81@yahoo.com, Mirzaee@merc.ac.ir) contribution of residual stress in grains. Also, Tang et al $l^{18}$ showed that the dielectric constant of $\mathrm{Ba}\left(\mathrm{Zr}_{0.2} \mathrm{Ti}_{0.8}\right) \mathrm{O}_{3}$ reduces with the decrease of grain size in the range of 2-60 $\mu \mathrm{m}$ which is due to the transition from normal to relax ferroelectric in small particles. Arlt et $a l^{19}$ also proposed that there is an optimum grain size of $0.8 \mu \mathrm{m}$ to reach the maximum dielectric constant. Generally, grain boundaries have undesirable effects on dielectric properties due to the accumulation of impurities, porosity and changes in ferroelectric domains. ${ }^{20}$

Materials with low dielectric constant can be applied as electrical insulators and can cause a fast signal transmission. Dielectric properties depend on the following parameters: porosity, the amount of crystalline phase, grain size distribution and density. The dielectric constant decreases with the increase on porosity and therefore study of the sinterability in dielectric properties is of great importance. ${ }^{18,21,22}$

Silica has valuable characteristics, such as low dielectric constant and dielectric loss, high melting point and chemical stability and low coefficient of thermal expansion which make it suitable for numerous applications. For example, low dielectric constant of silica reduces the thickness of parasitic capacitance, resulting in fast switching and less heat loss. ${ }^{23-26}$ Silica and $\mathrm{CaZrO}_{3}$ have nearly similar physical properties such as low thermal expansion coefficient and good thermal shock resistance. Therefore, studies on the preparation of composites with improved mentioned properties are considered.

In the current study, silica-calcium zirconate (CZS) nanocomposite was prepared according to the sol-gel method and their characteristics were investigated. Moreover, their thermal and dielectric properties were evaluated as well. 


\section{Experimental}

The chemicals used in this study to synthesize CZS nanocomposite were all of analytical grade. Stearic acid $\left(\mathrm{C}_{18} \mathrm{H}_{26}\right.$ $\left.\mathrm{O}_{6}\right)$, calcium acetate $\left(\mathrm{Ca}\left(\mathrm{CH}_{3} \mathrm{COO}\right)_{2}\right)$ were purchased from Merck, zirconium butoxide $\left(\mathrm{Zr}\left(\mathrm{OCH}_{2} \mathrm{CH}_{2} \mathrm{CH}_{2} \mathrm{CH}_{3}\right)_{4}\right)$ was provided from Sigma and nanosilica $\left(\mathrm{SiO}_{2}\right)$ was obtained from Razi adv. Mat.

\subsection{Synthesis of CZS nanocomposite}

CZS nanocomposite was prepared according to the sol-gel method as shown in figure 1 . Zirconium butoxide and calcium acetate with the molar ratio of 1:1 were first dissolved in stearic acid. Different weight percentages of silica $(80,85$, 90 and 95$)$ were then added to the prepared calcium zirconate $(\mathrm{CZ})$ sol. After heating and stirring at $80^{\circ} \mathrm{C}$, a transparent aqueous precursor solution was obtained. The precursor was then heated until the solution evaporated, leaving a soft, grey and aerated gel. The dried gel was calcined at 700, 900 and $1000^{\circ} \mathrm{C}$ for $4 \mathrm{~h}$ in air. Finally, CZS nanocomposite was produced successfully.

The characteristics of the prepared nanocomposite were studied by means of X-ray diffraction (XRD) (Philips D500), Fourier transform infrared (FT-IR) (Brukber-Vector 22), XRF (Oxford ED 2000) and SEM (Philips XL30) analyses. By adding $2 \mathrm{wt} \%$ of polyvinyl alcohol (PVA) and applying pressure $(150 \mathrm{MPa})$, pellets with diameter of $1 \mathrm{~cm}$ and thickness of $2 \mathrm{~mm}$ were prepared. Pellets were then sintered at $1300^{\circ} \mathrm{C}$ and covered with gold after that their capacitance were measured by LCR Meter instrument (AC voltage; $10 \mathrm{mV}$, frequency; 1-100HZ). The coefficient of thermal expansion was determined using a dilatometer (Model Netzsch DIL 402E) with the heating rate of $30^{\circ} \mathrm{C} \mathrm{min}-1$ and temperature range of $25-1200^{\circ} \mathrm{C}$.

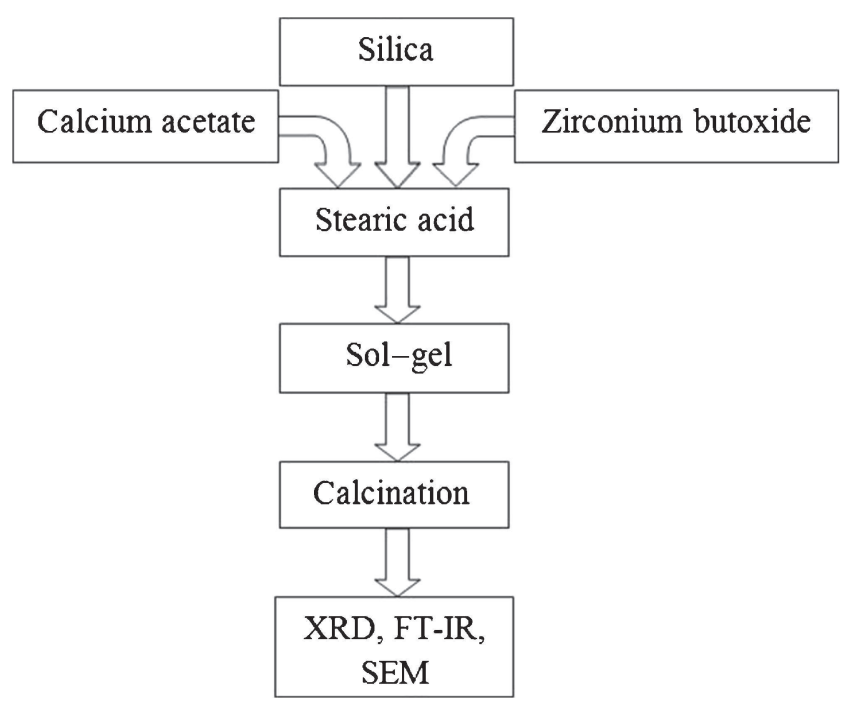

Figure 1. Schematic representation of silica-calcium zirconate nanocomposite synthesis with the sol-gel method.

\section{Results and discussion}

Table 1 shows the elemental analysis of natural nanosilica measured with XRF. It can be seen that the main component of silica is silicon dioxide and other elements including alumina, alkaline and alkaline earth oxides with low percentages. $\mathrm{XRD}$ analyses are shown in figures 2 and 3 and show that the $\mathrm{SiO}_{2}$ and $\mathrm{CZ}$ patterns were in agreement with the data in the JCPDS files (standard cards no. 01-085-0457 $\left(\mathrm{SiO}_{2}\right)$ and 01076-2401 (CZ)). It also demonstrated that CZ has orthorhombic structure. Moreover, the absence of phase impurity confirmed purity of these materials. SEM images of silica and $\mathrm{CaZrO}_{3}$ are illustrated in figures 4 and 5, respectively. Silica nanopowders were in spherical shape and their mean particle size was about $95 \mathrm{~nm}$, indicating the silica as a suitable matrix. SEM image of $\mathrm{CaZrO}_{3}$ nanopowder showed uniform particles with the average size of $75 \mathrm{~nm}$. Size distribution of silica and $\mathrm{CaZrO}_{3}$ are shown using Clemex Image Analysis version 3.5, which proved the uniformity of $\mathrm{CaZrO}_{3}$ nanopowder.

The XRD patterns of silica, CZ and CZS, respectively, as matrix, second phase and nanocomposite are compared in figure 6. The pattern of CZS nanocomposite shifted to the left direction in $30.13(2 \theta)$. XRD pattern of silica-5 wt\% calcium zirconate (CZS 5\%) indicated that CZS 5\% nanocomposite did not obtain and only silica peaks are

Table 1. XRF analysis of silica nanopowder.

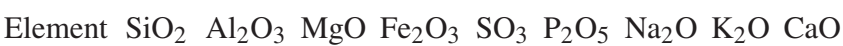

$\begin{array}{llllllllll}\text { wt } \% & 93.53 & 1.92 & 0.98 & 0.83 & 0.83 & 0.58 & 0.45 & 0.43 & 0.33\end{array}$

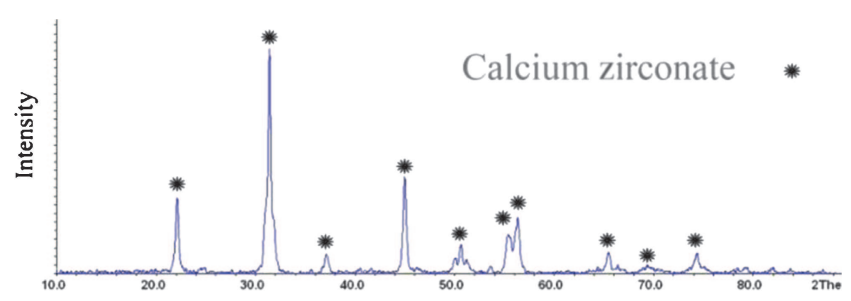

Figure 2. XRD pattern of $\mathrm{CZ}$.

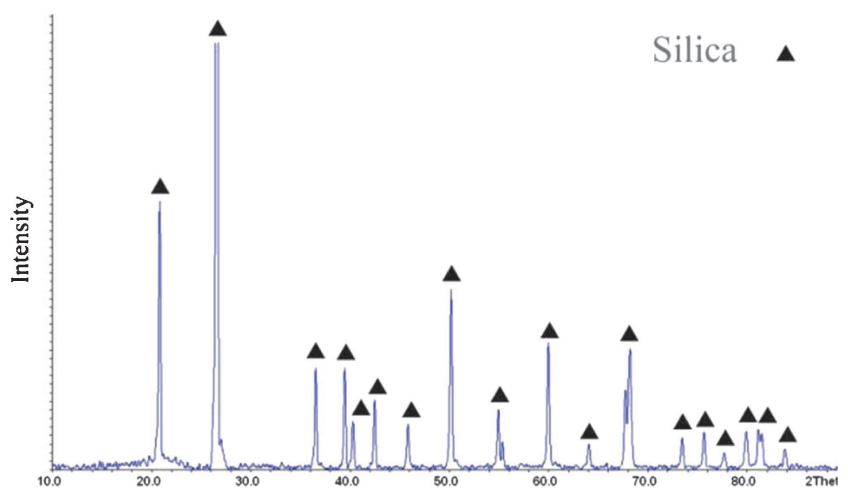

Figure 3. XRD pattern of silica. 

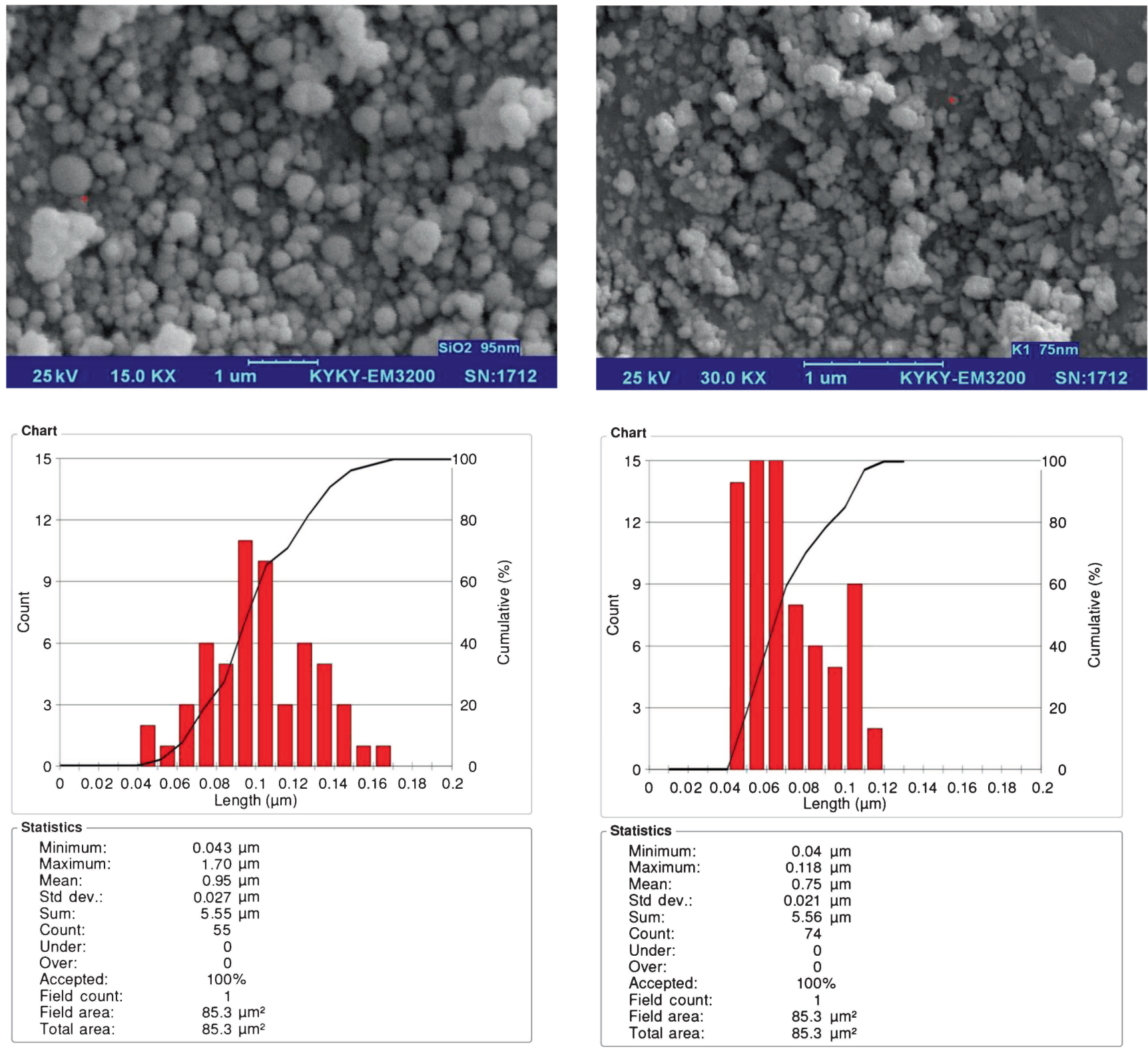

Figure 4. SEM image and size distribution of silica.

observed at the temperature of $700^{\circ} \mathrm{C}$ (figure $7 \mathrm{a}$ ). $\mathrm{CaZrO}_{3}$ peaks are appeared with increasing temperature to $900^{\circ} \mathrm{C}$ (figure 7b), implying the production of nanocomposite. Additionally, no change has been observed with enhancing temperature up to $1000^{\circ} \mathrm{C}$ and the sharpened peaks are only an indicative of grain growth (figure 7c).

Figure 8 illustrates the XRD patterns of $\mathrm{CaZrO}_{3}$ calcined at $900^{\circ} \mathrm{C}$. It can be seen that peak intensity was increased with enhancing $\mathrm{CaZrO}_{3}$ phase and an insignificant peak in 5 $\mathrm{wt} \%$ sample was converted to distinct peak in $34.73(2 \theta)$ in $20 \mathrm{wt} \% \mathrm{CZS}$ with increasing $\mathrm{CaZrO}_{3}$.

Figure 9 shows the FT-IR patterns of silica, $\mathrm{CaZrO}_{3}$ and nanocomposite calcined at $900^{\circ} \mathrm{C}$. The spectrum of CZS (figure 9c) is shifted to the lower frequency compared to the spectra of silica (figure 9a) and CZ (figure 9b), due to the presence of $\mathrm{Si}-\mathrm{O}$ covalent bonds in $\mathrm{CaZrO}_{3}-\mathrm{SiO}_{2} .{ }^{27,28}$

Figure 5. SEM image and size distribution of $\mathrm{CZ}$.

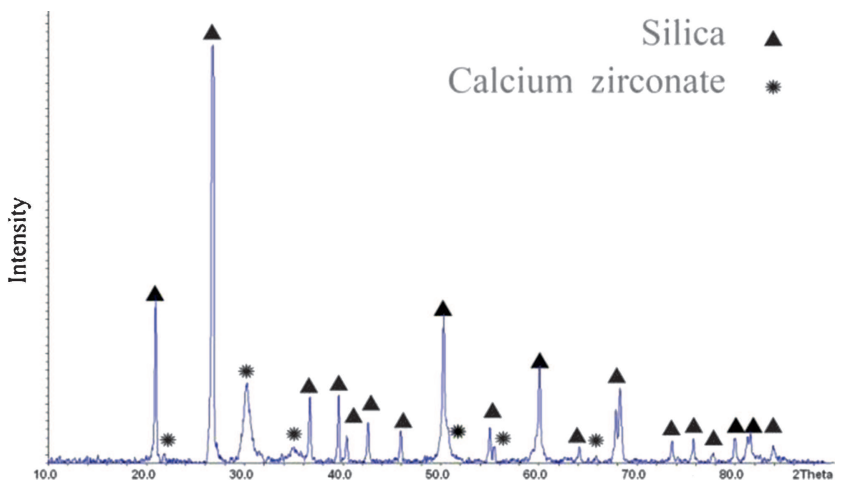

Figure 6. XRD patterns of (a) silica, (b) CZ and (c) CZS $20 \%$ after calcination at $900^{\circ} \mathrm{C}$. 
Thermal behaviour of nanocomposite was evaluated through the calculation of thermal expansion coefficient. Figure 10 demonstrates the thermal behaviour of silica, CZS $10 \%$ and CZS 20\% nanocomposites, over a temperature range of $25-1000^{\circ} \mathrm{C}$. The average value of thermal expansion coefficient for silica, CZS $10 \%$ and CZS 20\% nanocomposite were $15.96 \times 10^{-6}, 13.44 \times 10^{-6}$ and $10.2 \times 10^{-6} 1^{\circ} \mathrm{C}^{-1}$, respectively. It should be noted that, the coefficient of thermal expansion was decreased with enhancing $\mathrm{CaZrO}_{3} /$ silica ratio. Thus, the relationship between the nanocomposite components and coefficient of thermal expansion is calculated as follows: ${ }^{26,29}$

$$
\alpha=\alpha_{1}+\frac{\left(\alpha_{2}-\alpha_{1}\right) V_{2} E_{2}\left(1-2 \nu_{1}\right)}{V_{1} E_{1}\left(1-2 \nu_{2}\right)+V_{1} E_{1}\left(1-2 \nu_{1}\right)},
$$

where $\alpha$ is the coefficient of thermal expansion, $E$ the elasticity modulus, $V$ the volumetric content, $v$ the Poisson ratio, 1 and 2 are the matrix and secondary phase, respectively.

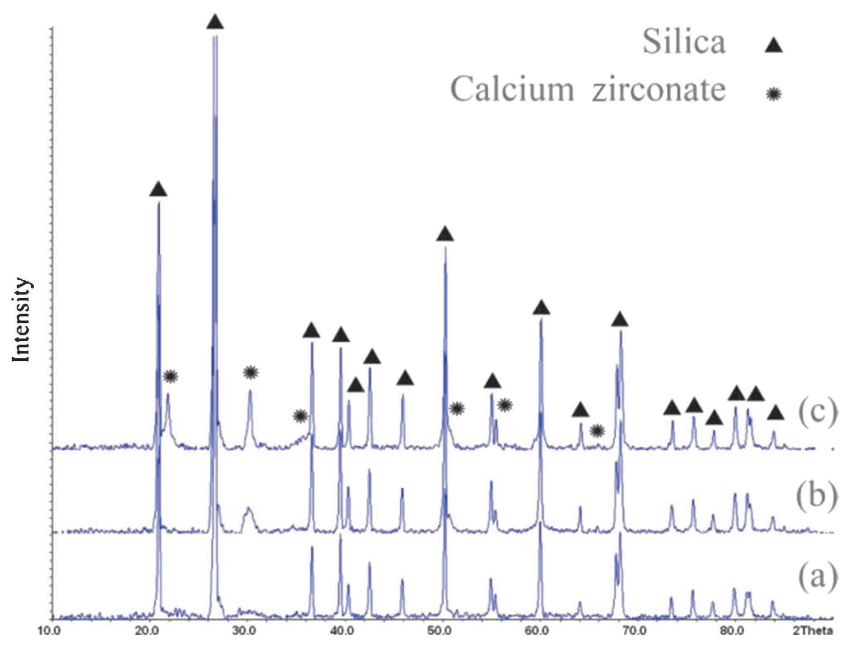

Figure 7. XRD patterns of $\mathrm{CZS} 5 \%$ calcined at (a) $700^{\circ} \mathrm{C},(\mathbf{b})$ $900^{\circ} \mathrm{C}$ and $(\mathbf{c}) 1000^{\circ} \mathrm{C}$.

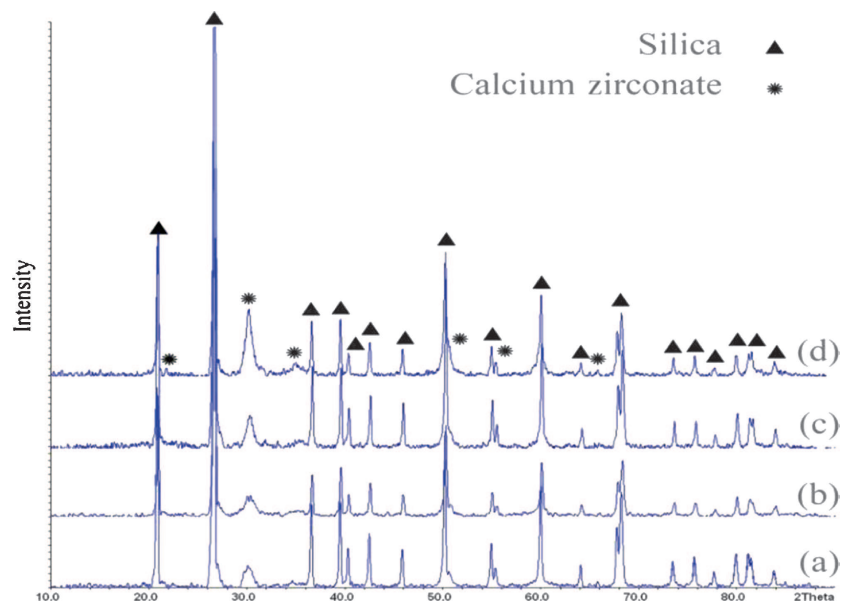

Figure 8. XRD pattern of (a) CZS 5\%, (b) CZS 10\%, (c) CZS $15 \%$ and (d) CZS $20 \%$ after calcinations at $900^{\circ} \mathrm{C}$.
The thermal expansion coefficient of silica-20 wt\% $\mathrm{CaZrO}_{3}$ nanocomposite was calculated using equation (1). According to this equation, the thermal expansion coefficient of $\mathrm{CZS}\left(10.26 \times 10^{-6} 1^{\circ} \mathrm{C}^{-1}\right)$ with 0.03 approximations $\left(10.29 \times 10^{-6} 1^{\circ} \mathrm{C}^{-1}\right)$ followed the equation (1).

Figure 11 shows the dielectric constants and losses of nanocomposite in the range of $1-100 \mathrm{kHz}$. As figure 11 clearly shows, the dielectric constant of nanocomposite was decreased from 7.24 in $1 \mathrm{kHz}$ to 5.85 in $100 \mathrm{kHz}$ with the increase of frequency. Dielectric constant of the calcined samples at the frequency of $100 \mathrm{kHz}$, and at temperatures of 700,900 and $1000^{\circ} \mathrm{C}$, were $4.71,5.29$ and 5.85, respectively. Also, dielectric losses of samples were 0.0351, 0.0422 and 0.05 , respectively. All the above-mentioned changes are attributed to the decreasing of space-charge polarization. ${ }^{30}$

The effect of the addition of $\mathrm{CaZrO}_{3}$ on the dielectric constant of the synthesized nanocomposite at $1000^{\circ} \mathrm{C}$ is shown in figure 12. It can be concluded that the dielectric constant of silica (dielectric constant of 4) was increased with the addition of $\mathrm{CaZrO}_{3}$ (dielectric constant of 27). This increase follows the equation (2) which is presented by Sheen et al ${ }^{21}$

$$
\varepsilon_{\text {mix }}-\varepsilon_{\mathrm{m}}=\frac{\left(\varepsilon_{\mathrm{d}}-\varepsilon_{\mathrm{m}}\right)\left(\varepsilon_{\mathrm{m}}+2 \varepsilon_{\mathrm{d}}\right)}{3 \varepsilon_{\mathrm{d}}} V_{\mathrm{d}},
$$

where $\varepsilon_{\text {mix }}, \varepsilon_{\mathrm{m}}$, and $\varepsilon_{\mathrm{d}}$ are the dielectric constant of composite, matrix and secondary phase, respectively, and $V_{\mathrm{d}}$ is the secondary volumetric content. Comparison of the mathematical calculations with the obtained results in table 2, imply that the obtained results follow the presented trend with $4 \%$ error.

As shown in figure 13 the dielectric constant was increased with the increase of calcination temperature and the calcined samples at $1000^{\circ} \mathrm{C}$ showed the highest dielectric constant, which can be attributed to the particle size of the nanocomposite (figure 14). Clearly, grain boundaries which are the main drawbacks of a system, can be decreased with enhancing grain size and thus have less undesirable results on the

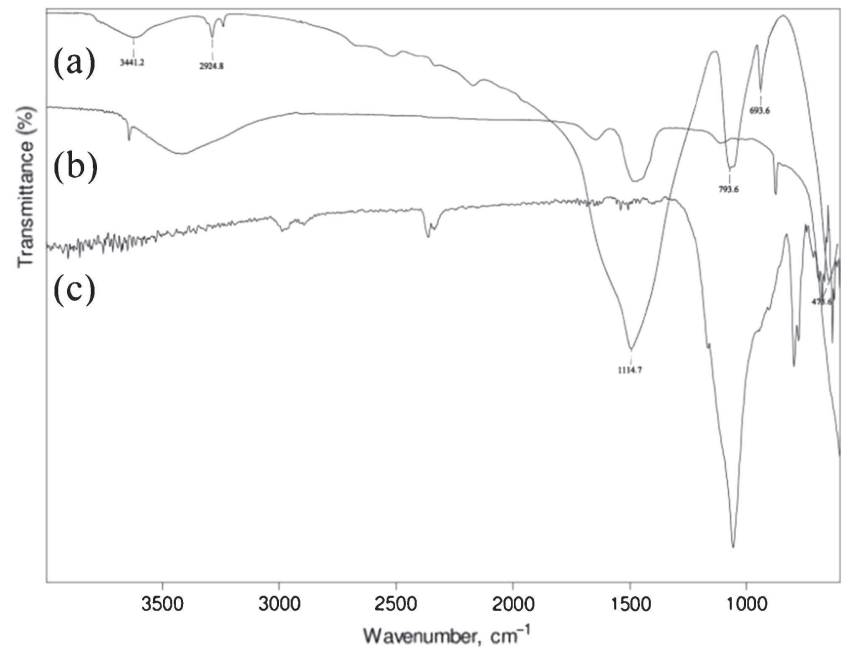

Figure 9. IR spectra of (a) silica, (b) CZ and (c) CZS 20\% after calcination at $900^{\circ} \mathrm{C}$. 


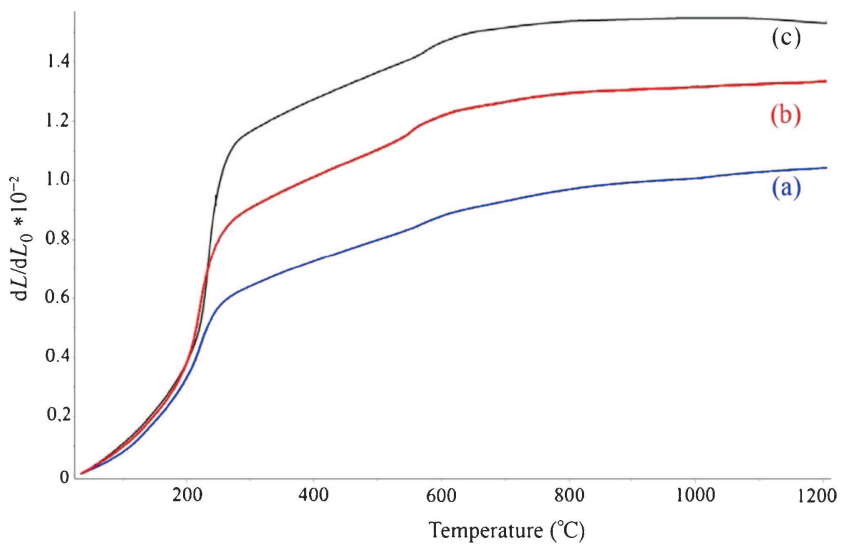

Figure 10. $\mathrm{d} L / L_{0}$ alteration of (a) CZS $20 \%$, (b) CZS $10 \%$ and (c) silica from 0 to $1200^{\circ} \mathrm{C}$ (dilatometer test).

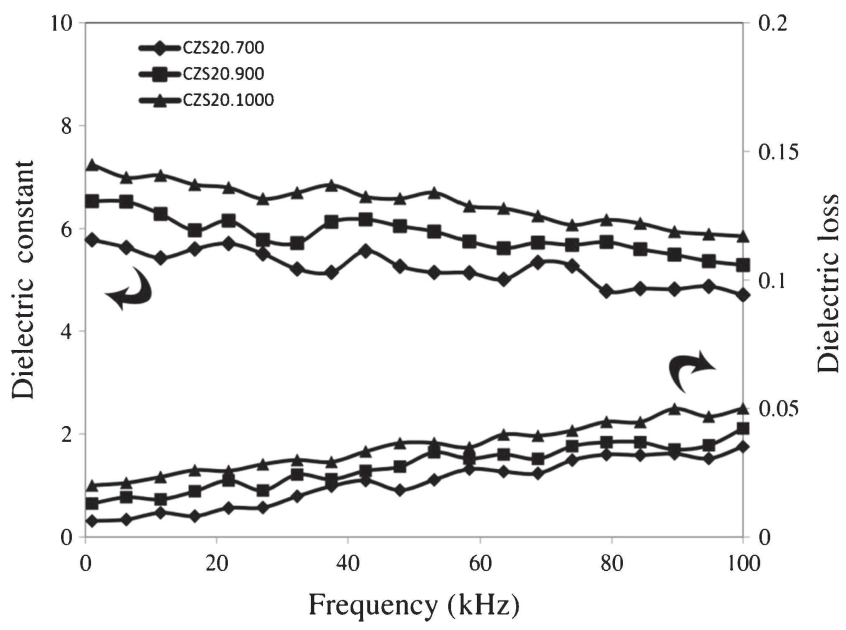

Figure 11. The plot of dielectric constant of silica-20 wt $\%$ calcium zirconate nanocomposite calcined at 700,900 and $1000^{\circ} \mathrm{C}$ from 1 to $100 \mathrm{kHz}$.

dielectric properties. SEM images of the sintered nanocomposites at $1300^{\circ} \mathrm{C}$ are shown in figure 14 . It is clear that with increasing calcination temperature from 700 to $1000^{\circ} \mathrm{C}$, particle size is increased from 0.383 to $0.886 \mu \mathrm{m}$.

\section{Conclusion}

In the present study, various weight percentages of CZS (5-20 wt $\%)$ were prepared successfully by the modified sol-gel method. Produced gel was calcined at temperatures of 700,900 and $1000^{\circ} \mathrm{C}$. The XRD patterns revealed that increase of $\mathrm{CaZrO}_{3}$ and temperature are highly effective on the nanocompsite formation. Also, the presence of $\mathrm{CaZrO}_{3}$ nanopowder in nanosilica matrix was confirmed. In FT-IR spectra, the effects of $\mathrm{Si}-\mathrm{O}$ covalent bonds on $\mathrm{Ca}-\mathrm{O}-\mathrm{Zr}$ bonds resulted in a shift of the frequency to the lower values $\left(\mathrm{cm}^{-1}\right)$. Conspicuously, the spectra of nanocomposite was different from the structures of $\mathrm{CaZrO}_{3}$ and silica, due to the fundamental changes of crystalline lattice, resulting in changes of the lattice formation energy, crystal energy,

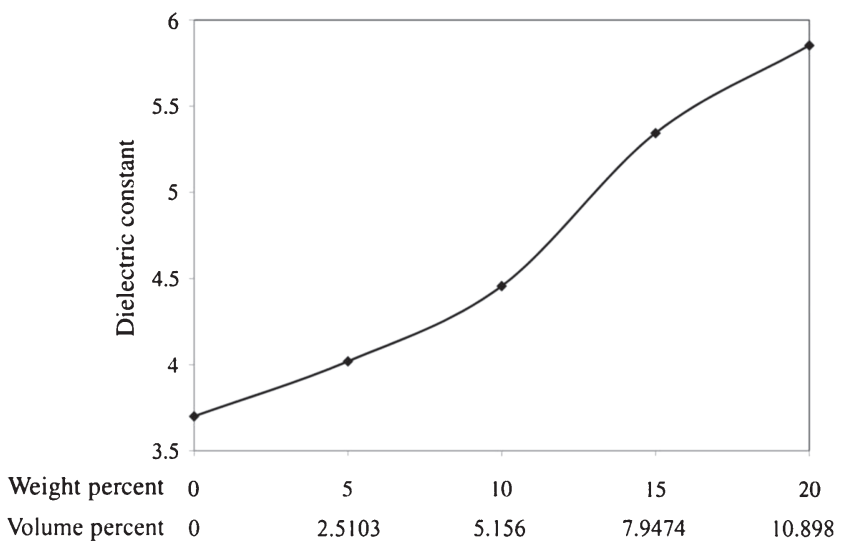

Figure 12. Effect of $\mathrm{CZ}$ content on dielectric constant of CZS calcined at $1000^{\circ} \mathrm{C}(100 \mathrm{kHz})$.

Table 2. Comparison of the theoretical and the experimental results for dielectric constant of CZS.

\begin{tabular}{lccc}
\hline Sample & $\begin{array}{c}\text { Experimental } \\
\text { value }\end{array}$ & $\begin{array}{c}\text { Calculated } \\
\text { value }\end{array}$ & Error \% \\
\hline $5 \%$ CZS & 4.0191 & 4.2170 & 4.924 \\
$10 \%$ CZS & 4.4559 & 4.6565 & 4.501 \\
$15 \%$ CZS & 5.3436 & 5.1202 & 4.181 \\
$20 \%$ CZS & 5.8525 & 5.6104 & 4.138 \\
\hline
\end{tabular}

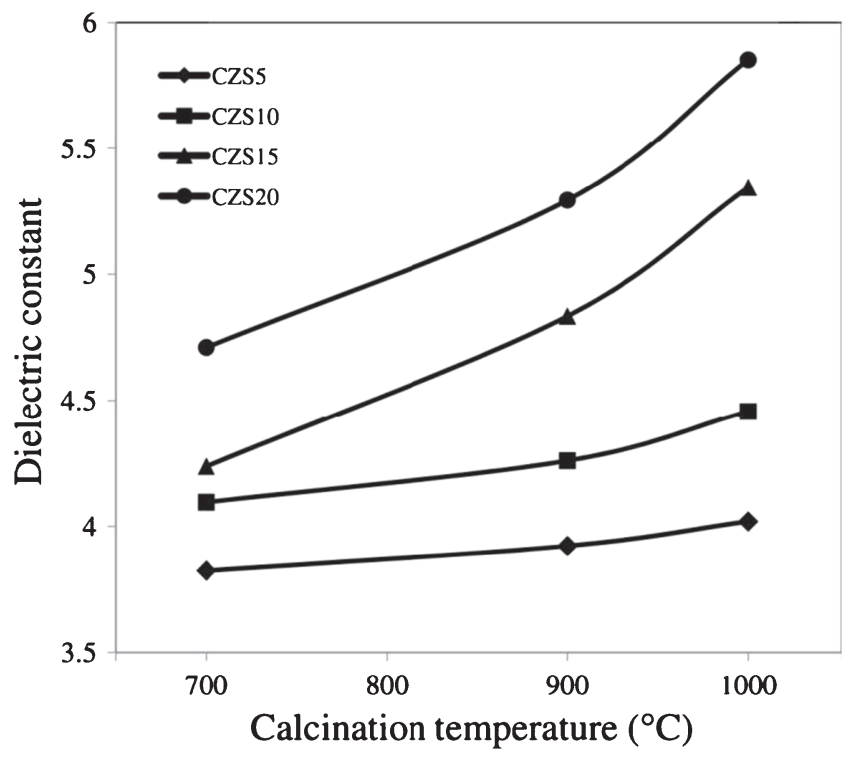

Figure 13. The effect of calcination temperature on dielectric constant of CZS $(100 \mathrm{kHz})$.

and stretching frequency of each bond. Moreover, the particle sizes of $\mathrm{CaZrO}_{3}$ and silica were calculated using SEM images, which were about 75 and $95 \mathrm{~nm}$, respectively. These findings indicated the fact that coefficient of thermal expansion was decreased with the addition of the $\mathrm{CZ}$ to the silica from $15.96 \times 10^{-6} 1^{\circ} \mathrm{C}^{-1}$ for pure silica to $10.26 \times 10^{-6}$ 


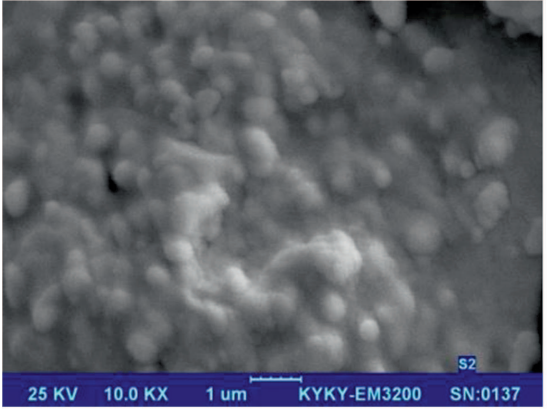

(a)

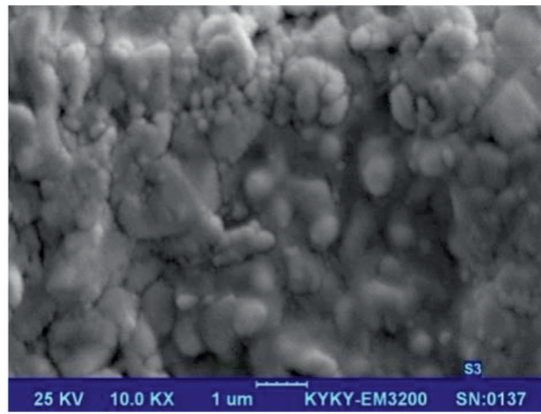

(b)

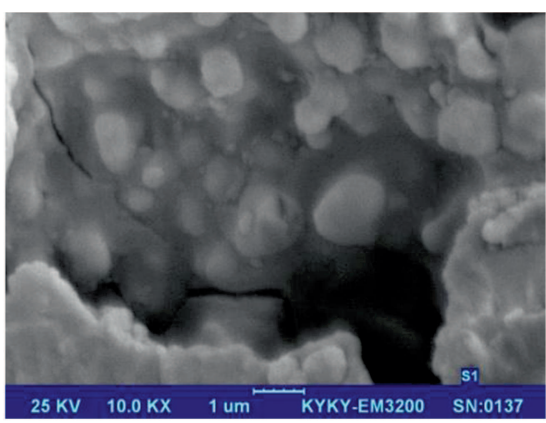

(c)

Figure 14. SEM images of CZS $20 \%$ calcined at (a) $700^{\circ} \mathrm{C}$, (b) $900^{\circ} \mathrm{C}$ and (c) $1000^{\circ} \mathrm{C}$.

$1{ }^{\circ} \mathrm{C}^{-1}$ for $\mathrm{CZS} 20 \%$. Results showed that dielectric constant of the produced nanoparticles decreased with the increase of frequency. Additionally, dielectric constant of the nanocomposite was increased with enhancing $\mathrm{CaZrO}_{3}$ phase and temperature. Dielectric constant of 5.8 and thermal expansion coefficient of $10.26 \times 10^{-6} 1^{\circ} \mathrm{C}^{-1}$ for $20 \%$ nanocomposite are an indicative of an optimized conditions in comparison with other composite percentages.

\section{References}

1. Rog G, Dudek M, Kozlowska-Rog A and Bucko M 2002 Electrochim. Acta $\mathbf{4 7} 4523$

2. Dudek M and Drozdz-Ciesla E 2009 J. Alloys Compd. 475 846

3. Ross N L and Chaplin T D J 2003 J. Solid State Chem. 172123

4. Prasanth C S, Kumar H P, Pazhani R, Solomon S and Thomas J K 2008 J. Alloys Compd. 464306

5. Yu T, Zhu W G, Chen C H, Chen X F and Krishnan R G 2004 Physica B: Condens. Matter 348440

6. Dudek M and Bucko M M 2003 Solid State Ion 157183

7. Dravid V P, Notis M R and Lyman C E 1987 J. Mater. Sci. 22 4546

8. Levin I, Amos T G, Bell S M, Farber L, Vanderah T A, Roth R S and Toby B T 2003 J. Solid State Chem. 175170

9. Serena S, Sainz M A and Caballero A 2004 J. Eur. Ceram. Soc. 242399

10. Jonas S, Nadachowskis F and Szwagierczak D J 1998 Ceram. Int. 24211

11. Stoch P, Szczerba J, Lis J and Madej D Pedzich Z 2012 J. Eur. Ceram. Soc. 32665
12. Nadler M R and Fitzsimmons E S 1955 J. Am. Ceram. Soc. 38 214

13. Bin T, Ren Z S, Ying Y, Hua Z X and Shuai L Y 2008 Sci. China Technol. Sci. 511451

14. Ianos R and Barvinschi P 2010 J. Solid State Chem. 183491

15. Hwang S C and Choi G M 2008 Solid State Ion 1791042

16. Wang C C, Chen W H, Akbar S A and Alim M A 1997 J. Mater. Sci. 322305

17. Buessem W R, Cross L E and Goswami A K 1966 J. Am. Ceram. Soc. 4933

18. Tang X G, Wang J, Wang X X and Chan H L W 2004 Solid State Commun. 131163

19. Arlt G, Hennings D and With G D 1985 J. Appl. Phys. 581619

20. Moulson A J and Herbert J M 2003 Electroceramics: materials, properties, applications (Wiley and Sons) 2nd ed

21. Sheen J, Hong Z W, Liu W, Mao W L and Chen C A 2009 Eur. Polym. J. 451316

22. Oh J T, Hing P and Fong H S 1999 J. Mater. Process. Technol. 89-90 497

23. Mollá J and Ibarra A 2004 Nucl. Instrum. Phys. Res. Sec. B, Beam Interact. Mater. Atoms 218189

24. Jaln V, Varshneya A K and Bihuniak P P 1990 J. Am. Ceram. Soc. 73409

25. Ding S, Zeng Y P and Jiang D 2007 Mater. Lett. 612277

26. Chen S, Zhang S, Zhou X and Wen Z 2011 J. Alloys Compd. 5094848

27. Selvam N C S, Manikandan A, Kennedy L J and Vijaya J J 2013 J. Colloid Interface Sci. 38991

28. Hu Q, Suzuki H, Gao H, Araki H, Yang W and Noda T 2003 Chem. Phys. Lett. 378299

29. Eberstein M, Glitzky C, Gemeinert M, Rabe T, Schiller W A and Modes C 2009 Int. J. Appl. Ceram. Technol. 61

30. Song X, Fu R and He H 2009 Microelectron. Eng. 862217 